\title{
El Jesuita padre Francisco Villanueva (1509-1557): Prototipo de un nuevo apóstol en la Castilla de la reforma católica ${ }^{1}$
}

\author{
ALFREDO VERDOY*
}

La riqueza historiográfica de la España del Antiguo Régimen es tan rica y variada que nunca por mucho que la estudiemos llegaremos a conocerla. Desde esta tesitura y en el contexto del siglo XVI, creo vale la pena presentar un gran desconocido: el jesuita padre Francisco de Villanueva (1509-1557), el primero de los jesuitas españoles que se asentaría, siguiendo el modo de proceder de Ignacio de Loyola y de sus primeros compañeros, en la ya floreciente Universidad de Alcalá.

Nuestro propósito no es otro que el de ofrecer a los investigadores de la España religiosa y secular del Antiguo Régimen el perfil, las maneras, los trabajos y los objetivos apóstolicos de uno de los adelantados de la joven Compañía de Jesús en la Universidad de Alcalá y en el reino de Toledo y demostrar cómo sus pasos, en cierta medida, fueron seguidos y renovados por sus sucesores hasta su extinción en 1773 como orden religiosa.

La documentación será en gran parte inédita. Procede, fundamentalmente, de la Historia del Colegio Complutense de la Compañia de Jesús. Compuesta por el P. Cristóbal de Castro, Lector de Escritura en el mismo Colegio y en trece libros repartida. Compluti. Anno M. D. C. 1600.

Castro, que utiliza la retórica y pone la historia al servicio del evangelio, además de ser un consagrado narrador, es maestro en el uso de la paradoja y el contraste. Villanueva brilla más cuanto más se le empequeñece y se le compara con los sabios y maestros de la famosa Universidad Complutense; no duda presentarlo como «un Hermano idiota y sin letras

Universidad de Comillas

Astraln. A. M., Historia de la Compañia de Jesus en la Asistencia de España. Madrid 1912 y 1905, t. I y II; Rouges, J. C., El estudio hecho oración en la ensenaanza de San Ignacio. Santa Fe (Argentina), tomos I y II, 1960; O'MALLE', J., Los primeros jesuitas. Bilbao, 1995. 
en una Universidad de tantas letras; un hombre desconocdo y destituido de todo genero de favor humano, entre gente de tanta autoridad y favorecida de los hombres" "2 que logró hacer de su colegio y de los ministerios que en él se practicaban «el más copioso y mas util Seminario, que la Compañia ha tenido para ser proveída de gente ${ }^{3}$. Fue precisamente en la Universidad de Alcalá, lugar "donde su primer instituidor y fundador Ignacio estudió, con tres de sus primeros compañeros" ${ }^{4}$, donde se desarrolla la vida y la historia que queremos presentar.

Nuestro artículo constará de ocho apartados, en los que tras la presentación sumaria de su biografía, se estudiarán los rasgos constitutivos de su personalidad; rasgos, que de alguna manera, se encarnarán en las nuevas generaciones de jesuitas, protagonistas religiosos y políticos de la España Moderna. No prentendo levantarle un monumento hagiográfico, que bien merecido, por otra parte, lo tiene, sino conocer mejor, a través de su persona, un nuevo tipo de religioso y una nueva manera de entender y llevar adelante el anuncio del evangelio en una España en permanente cambio, en la que la conversación y los coloquios, la predicación y los sacramentos, la devoción y el entusiasmo religioso, la irreprimible esperanza en la bondad de la naturaleza caída y la acción misteriosa de la oración, se fueron combinando y readaptando hasta transformar la vida religiosa del pueblo, enseñándole a discernir el paso de Dios por su vida y por el mundo, realidades, en nada, exentas de indiscreciones y excesos espirituales ${ }^{5}$, donde era muy fácil mezclar la acción benéfica de Dios con la acción maléfica del mal.

Repito, no me interesa ir tras los pasos de Villanueva, sino pararme indiscretamente en aquellos lugares por los que transitó su espíritu y sorprenderme con sus maneras de hacer y proceder, novedosas en el panorama apostólico español de la época. En Villanueva destacan algunas de las notas identificativas de los primeros compañeros de Ignacio de Loyola, a los que cabe calificar, rompiendo manidos exclusivismos que ponen y asientan la nueva orden en su sola persona, de auténticos fundadores de la nueva orden. Estas notas, sobre las que se vertebrará este artículo, serán: su itinerancia exterior e interior, o lo que en el lenguaje de

Historia del Colegio Complutense, pág. 2

Ibidem, pág. 2

Ibidem, pág. 5.

En algunas de sus salidas del Colegio del Alcala, "hubo penitencias excesivas de cuatro disciplinas al dia y no pocas de mucha sangre, cilicios y jubones de espinas y rebolearse (sic) sobre las ortigas de la huerta que eran muy grandes y otras invenciones... y en ninguna manera se hablaba uno a otro". Ibidem. pág. 258. 
la ascética de siempre se llama la peregrinación; su desbordante entusiasmo apostólico y su «inoportuno» celo pastoral, especialmente en la propagación, uso y adaptación de los Ejercicios Espirituales; su radicalismo e ingenuidad en el seguimiento del Señor; su constante y permanente devoción; su carácter carismático en la construcción de una comunidad de apóstoles; su confianza a pesar de la desproporción entre los medios y los fines en el éxito final; su libertad interior y su inagotable capacidad creativa e imaginativa a nivel apostólico; su peculiar interpretación y adaptación de la naciente espiritualidad jesuitica y, por último, su fuerte carácter y personalidad, condición y presupuesto básico de su vida y acción apostólica.

\section{PERFILES BIOGRÁFICOS}

Francisco de Villanueva nació "de honrados labradores» en Villanueva de la Vera el año 1509. Fue criado cristianamente y durante su niñez cle enseñaron a leer y escribir»; "en su mocedad hizo oficio de sacristán en otro lugar de la misma Vera, que se dice el Losar". Ingresó en la Compañía de Jesús en Roma en 1541; su maestro de novicios fue el mismo Ignacio de Loyola; Alfonso Salmerón le acompañó y exhortó durante el mes de Ejercicios, experiencia que marcará su vida y orientará sus apostolados. En su noviciado, poco más de un año, fue duramente probado; además de vencer las típicas pruebas que todos los jesuitas deben superar, le acometieron los escrúpulos, no faltándole tampoco ocasiones para abandonar su nueva vida; desde un principio se le encomendaron tareas, al parecer, imcompatibles para un novicio entre el supuesto orden de su nueva vida y el agobio de cada día como atender la cocina, comprar y despertar a la comunidad de la casa de Roma. Estilo de formación que tratará de inocular a los que forme y pruebe.

Superado el noviciado con el refrendo de su maestro, Ignacio de Loyola, fue enviado al naciente Colegio de Coimbra (1542); en Portugal se le quebró la salud y a los pocos meses era puesto de nuevo camino de Roma; a su paso por Alcalá, y siempre por mandato de Loyola, se detuvo a saludar a los que no hacía muchos años habian protegido a Ignacio y a sus primeros compañeros; y lo que se pensaba duraría unas semanas se convirtió en la práctica en su único destino.

En Alcalá, al tiempo que intentaba estudiar para ordenarse sacerdote, se dedicó con desigual suerte a los ministerios espirituales, que por aquellos dias se inauguraban en la península, a la dirección de un incipiente colegio de estudiantes jesuitas, a la defensa de los privilegios de su orden, 
a la popularización de los Ejercicios Espirituales y a la fundación de tres nuevos colegios para externos en Córdoba (1553), Plasencia (1555-1557) y Ocaña (muy intermitentemente).

\section{El peregrino}

Villanueva, como todos los grandes de su época, fue un auténtico andariego; de Roma, ciudad a la que llegó comisionado por el párroco del Losar para resolver asuntos beneficiales, viajó siempre a pie, pues «tenía la costumbre de hacer todos sus caminos a pie con el manteo al hombro y con su breviario y un contemptus mundi» ${ }^{6}$; su primer viaje por mar y tierra fue a Coimbra; de Coimbra a Alcalá; ciudad que hará suya, para desde allí peregrinar, continua y permanentemente, siempre a pie, a cuantos lugares le enviasen la predicación, los ejercicios espirituales, los litigios de la primera Compañía y las nuevas fundaciones.

Toledo, en repetidas ocasiones, la sierra madrileña y Segovia, las riberas del Henares, la Alcarria, Toledo, Guadalajara, Madrid, Cuenca, Córdoba, Plasencia, Salamanca, Valladolid, Lisboa, Ocaña, le vieron transitar en las más variadas circunstancias. La estación más propicia para estos viajes, a pesar de las fuertes calores, era el verano. Durante las vacaciones estivales sólo, como ya hemos dicho, y las más de las veces en compañía de sus estudiantes recorria los tórridos campos castellanos para anunciar la palabra de Dios. Si Villanueva, como tendremos ocasión de ver más adelante, hizo de la recoleta y estrecha cocina de su pobre colegio una cátedra durante el largo invierno de Castilla, los veranos hacía todo lo posible para que ésta se ampliase a los caminos, plazas y poblaciones, aldeas, villorrios y capitales, donde se solazaban y entusiasmaban sus devotos y deudos. Villanueva, en su faceta de formador, era amigo de acostumbrar a sus estudiantes a "que anduviesen a pié y ansí los veranos en tiempos de vacaciones los embian (sic) peregrinando a algunos lugares donde habia devotos de la Compañía como a Galapagar, a Cuenca, a Siguenza y otros donde venían otros movidos con el exemplo y trato de los Hermanos a hacer exercicios personas de cuento". Por todo esto y por el poco miedo que le tenía al polvo y a las malas posadas, "el doctor Vergara le llamaba mi peregrino"?

lbidem. pág. 201

Ibidem. pág. 564 rep. 
11. El apóstol y el ejercitador, el varón lleno de celo apostólico que lucha por el reconocimiento de los Ejercicios

A Villanueva le cuadran estas expresiones por antomasia. Todo en él, desde que se levantaba hasta que rendido se acostaba, estaba orientado a enseñar a descubrir en sus prójimos la presencia misteriosa de Dios. Significativa nos parece una carta escrita de su mano a un joven sacerdote, que más tarde sería insigne predicador entre los jesuitas, el doctor Ramírez, para entender cuáles eran sus motivaciones apostólicas. Ramírez dudaba si hacerse o no jesuita; preferia la libertad de su estado sacerdotal y temía vincularse de por vida a empresas en las que su imaginación le decía que nunca gobernaria a su placer; Villanueva, conocedor por experiencia propia y ajena de estos y parecidos trances, en carta del 12 de enero de 1555, le confesaba que sus dubitaciones y miedos le recordaban los que había pasado hacia años, antes de entrar en la Compañia, y que por experiencias posteriores bien valía pasar. Comparaba la vida cristiana y el seguimiento del Señor al salto del carroyo de la libertad o por mejor decir del captiverio de la obediencia de tantos temores, tantas reveliones (sic) a "la libertad del paraiso terrenal de la obediencia", salto arriesgado y en el que saltador siempre "hallaba alli un muro de revelión (sic) que me detenía". Villanueva, que había sufrido mucho en el seguimiento del Señor, pero que al mismo tiempo se había descolgado casi en el vacío, quería con su vida dar la mano a los medrosos y timoratos para que saltaran lo más confiadamente posible del arroyo del egoísmo al reino de la libertad y de la presencia liberadora del paraíso; sabía que una vez que el ser humano sintiese el fuego del amor de Dios nada ni nadie le impedirian saltar. Si se querían saltadores, es decir cristianos, la mejor ayuda era enseñarles a gustar la presencia de Dios. A esta misión dedicará toda su vida.

Su celo le arrastraba a tratar con toda clase de personas: hombres y mujeres, grandes y pequeños, frailes y laicos, ricos y pobres, instruidos y analfabetos; su templo y capilla no tenían fronteras ni muros; buscaba y encontraba a la gente por tiendas, calles y rastros, por plazas, fuentes y cruces de caminos; se citaba con ellos en posadas y ventas; los zaguanes de las iglesias y palacios, las largas estancias y corredores de los hospitales y asilos y hasta los más míseros tugurios constituian su "templo"; alli en lugares que les eran familiares, cada cual su manera, era exhortado a la virtud y a la práctica de los sacramentos, sólo a los que veía "más capaces, a los espirituales ejercicios... con que solia él hacer su negocio, o por mejor decir el negocio de Dios", les invitaba a entrar en ellos.

A todos a los que se dirigía les llamaba la atención la fuerza que tenía para atraer gente «al servicio de Dios y al frecuente uso de los sacramen- 
tos" ${ }^{8}$. Hablaba de Dios con razones buenas y eficaces; desbarata los argumentos que los doctores de teología le oponian. Dominicos tan letrados y esclarecidos como los doctores Muncio y Cano, quedaban sorprendidos de su ciencia y capacidad para comunicarla; el primero, "se le estaba oyendo una y dos horas»; el segundo, el correoso Cano, solía decir: "no he topado yo Theologia como la de Villanueva y otras veces decir que estimaba el mas la Teología de Villanueva que la de quantos habia en la Universidad y que hacia gran ventaja a la suya que con tanto estudio y en tantos años habia aprendido» ${ }^{9}$. Algo parecido opinaba el doctor Vergara, regustándose "cuan bien hablaba (Villanueva) de Dios y cuan atentamente, cuan vivas eran sus razones no aprendidas en escuelas, ni sacadas de los libros, con qué espíritu y cuan de veras las decía y cuan impresas las dejaba en el corazón» ${ }^{10}$. Otros muchos "echaron de ver el singular don que Dios le había dado para hablar, y especialmente de Dios, todos le reverenciaban y procuraban hablar con él»" ${ }^{11}$. Era bastante frecuente ver "gente letrada y docta y ansi de ordinario en nuestro patio solía estar rodeado de Doctores, colegiales, mayores y religiosos que le venian a oyr y tratar con él sus negocios" ${ }^{12}$.

Contenidos que no se correspondían, absolutamente nada, con su forma, bastante descuidada y atrabiliaria, de vestir. Para Villanueva lo menos importante era su facha exterior, lo esencial era el contenido y el tono con el que hablaba de Dios. Bartolomé de Torres, catedrático de la Universidad de Sigüenza, se encontró con él por primera vez «un rato que estaba haciendo unas tapias de la huerta de casa" y volvió "lieno de admiración a unos padres que alli cerca vió y dixoles: 30 años ha que ando entre Scotos, Durandos y Stos Thomas y los demas teologos escolásticos y nunca he topado en ellos razón tan fuerte que de una manera $u$ otra se pueda saltar y deshacer más a las razones de Villamuera (que así le llamaba por gracia) no hallo solución porque me atan de pies y de manos ${ }^{13}$.

Ibidem, pág. 74 .

Ibidem, pág. 573

Ibidem, pág. 111. Este modo de predicar ha sido estudidado por Malley, págs. 119-135 y coincide especialmente con lo que dice aqui el biografo de Villanueva. El mismo Vergara en carta al Padre Miguel de Torres le comentará este primer encuentro con Villanueva en carta del 18 de junio de 1548: "yo he comunicado algo de la materia de la Santa Compañia con mi Padre Villanueva, el cual me ha dado Dios por despertador de mi alma, y angel de guarda: lo que siento en mi es, que me pesa lo tarde que lo comenzé a gustar, y lo poco que lo he continu:irto. espero en Nuestro Señor con su favor de lo acabar, y porque no falta el Capitán que me implik con toda la posible artilleria, ruego a VM y a los hermanos, que allá están, me encomienden a Vuestro Señor para que de el perficiere, pues ha dado a sentir lo que es, y para mostrar por las obras la voluntad verdadera y el sentimiento que habia cobrado de la Compañian. Ibidem. pág. 113.

lbidem, págs. 43-44.

lbidem, págs. 574-575.

lbidem, págs. 573-574 
A las mujeres, cosa mal vista en su tiempo, siguiendo el ejemplo de Loyola, Pedro Fabro y Araoz les daba con frecuencia ejercicios; a las casadas les enseñaba «lo que el apostol enseña a Timoteo y a Tito su discípulo, que estén obedientes a sus maridos, crien a sus hijas y rigan (sic) bien sus casas, sean hacendosas, no hagan mudanzas»" ${ }^{14}$.

Su amor a los Ejercicios era tan grande, que al no estar éstos aún suficientemente aprobados y reconocidos, no temía ser perseguido y tachado de alumbrado. Por esto muchos recelaban de él y de sus novedosos métodos. Convencido como estaba de la bondad de los mismos, porfiaba con cuantos veía capaces y les animaba a zambullirse en ellos como hizo con un clérigo, llamado Zavallos, "para ver qué cosa eran y qué doctrina se contenia en ellos». Zavallos, acompañado del Capellán mayor de San Ildefonso y de Sevillano, amigo común de los tres, se recogieron en la ermita, "que se dice de S. Sebastián, media legua de Galapagar, junto a Colmenarejo"; los frutos no se hicieron esperar y a su vuelta Sevillano se fue a vivir donde moraba Villanueva.

Su vida fue una continua apuesta por los ejercicios; poco a poco fue acrecentándose el número de personas que movidas por «el buen ejemplo de vida... asi por su modestia y caridad que en su trato experimentaban, como por las continuas pláticas, que con ellos tenían, que todos echaban centellas de devoción", los practicaban. "Muchos estudiantes y gente mayor pedian ser admitidos a hacer los ejercicios" ${ }^{15}$. Entre los de más edad, cabe destacar al Magistral de Cuenca, Doctor Vergara, quien estando en Alcalá, más para olvidar penas que para otra cosa, salió de los Ejercicios con "confesión general" y "tan otro y tan rendido a la virtud, que no era dificultoso echarselo de ver, y de su confesión tan contento que dijo a los nuestros: alabad a Dios que de cuantas confesiones he hecho en mi vida de ninguna he salido tan satisfecho como de ésta" ${ }^{16}$; el Conde de Melito, después Duque de Francavila, un prior de Canarias, el doctor Francisco Sánchez, abad de San Juste en Alcalá, el franciscano con fama de santo y amigo personal de Villanueva fray Juan de la Parra y "Gaspar de Quiroga Canonigo de Toledo, que después vino a ser Arzobispo de aquella Iglesia y Cardenal»...

El éxito alcanzado por la práctica de los ejercicios le causó tan graves problemas que como había ocurrido a otros anteriormente, se vio en la

\footnotetext{
Ibidem, pág. 583.

Entre ellos destacaron Baptista de Barma, Juan Gamero y el sacerdote granadino maestro Padre de Sylva, Ibidem 124-125; $125-128$ y 126-127.

Ibidem, pág. 112
} 
obligación de enseñar "a los más principales de la Villa y Universidad las Bulas de la aprobación y confirmación de la Compañia para que acabasen de persuadirse ser Religión verdadera aprobada por la Sede Apostólica" ${ }^{17}$.

Su singular manera de proceder en lo apostólico, como ya se ha dicho, levantó graves sospechas y denuncias. Tres puntos fueron los que más molestaban a las autoridades religiosas del arzobispado de Toledo, diócesis a la que pertenecía Alcalá a la sazón: la frecuencia de sacramentos, el modo de vida de la nueva religión y la práctica de los Ejercicios Espirituales ${ }^{18}$.

Las denuncias, ahora en manos de un enrabietado Siliceo, determinaron en gran parte su acción en defensa de los ejercicios y de los ejercitantes ante el arzobispo de Toledo. La reacción de Siliceo no pudo ser más contraria a los intereses de Villanueva y sus hombres: el arzobispo detuvo, en primer lugar, no sólo a algunos de sus sacerdotes, que estando bajo su jurisdicción, habian hecho los Ejercicios, sino que "por públicos edictos» les revocó sus licencias sacramentales; en segundo, importunó a los jesuitas hasta hacerles salir de Alcalá, o en su defecto expulsarlos y someterlos a su entera jurisdicción ${ }^{19}$; en tercero, les amenazó con promulgar edictos de excomunión mayor, latae sententiae, "a todos los Curas y beneficiados y súbditos de su Arzobispado», que admitiesen a alguno de la Compañía a predicar, confesar, administrar sacramentos algunos en sus Iglesias, prohibiéndoles, igualmente, les diesen recaudo por celebrar la misa.

Harto y con él todos sus compañeros de tantas afrentas y frenos a su aprobado y experimentado modo de proceder, el padre Francisco de Borja mandó que los prohombres que por entonces gobernaban la Compañía, Miguel de Torres, Pedro Tablares, Araoz y el propio Villanueva, visitasen al arzobispo.

Si traemos la defensa que los jesuitas hicieron de su instituto y de sus Ejercicios Espirituales es principalmente para mostrar, primero, la actuación de Villanueva y transparentar, en su segundo momento, su talante y

\footnotetext{
Ibidem, pág. 129.

18 "Dicenle, cuenta nuestro cronista, que en su Arzobispado había ciertos clérigos, que ha. bian hecho asiento en Alcalá exemptos de su jurisdicción, que confesaban y predicaban y exortaban (sic) a ejercicios espirituales y se les llamaba de la Compañia de Jesús, y que era bien examinarlos no introdujesen alguna falsa doctrina, porque como gente nueva metian nuevas costumbres con no sé que ejercicios que daban y mucha frecuencia de sacramentos, nunca antes vista, ni oida y que dentro de Toledo habia más de quinientos teatinos, asi de Clérigos, como de legos y casados, hombres y mujeres". Para allegar personas a su devoción, admitian a "los Sacramentos contra el Orden de la Santa Iglesia; dejando algunos de ellos dejar a sus penitentes comulgar dos veces al dia". Ibidem, pág. 184

14 Textos tomados de las págs. 183-186.
} 
personalidad. La primera visita, concertada para el 24 de junio de 1551, de nada sirvió. Villanueva, que nada tenía que perder, partió para Madrid y el seis de noviembre dirigió una provisión al Consejo Real, en la que pedia que dicho Consejo «intimidase las Bulas a cualquier Prelados o Jueces eclesiásticos, y a otras cualesquiera personas que fuese necesario lo hiciesedes ${ }^{20}$. Villanueva, que ante todo queria la paz, intentó de nuevo entrevistarse con Silíceo; acudió a Toledo, acompañado, una vez más, del padre Miguel de Torres; en esta ocasión, al hilo de su defensa, salió todo cuanto pensaban, unos y otros, del Papa, de las órdenes religiosas asi como de algunos asuntos político-religiosos del momento; "sospechaba, Siliceo, que el papa Paulo no supo lo que hizo en probar y confirmar la Compañía»; el papa, decia, no podía "dar licencia a los de la Compañía para predicar y confesar y los demás derechos", si lo hacía, "de hecho lo hacía mal»; es más, el mismo "le diría que no lo podia hacer y que se lo probaria, porque se había quemado más las cejas para estudiarlo que no él». La Compañia había sido aprobada, insinuó Torres, afirmación a la que respondió Silíceo: «que ser aprobada no le era fundamento a él para la tener por buena, antes para poner en ella sospecha". El diálogo continuó, equiparando los jesuitas su aprobación a la de las otras órdenes, a lo que les respondió que éstas estaban «aprobadas por milagros". Como se deslizase el diálogo por los trillados caminos de la soberanía y poder jurisdiccional y espiritual del papa, Siliceo se fue poniendo cada vez más ufano hasta a afirmar con respecto «a lo de las licencias que los Papas de estos tiempos no tenían cuidado de aprovechar las almas, sino de hacer mayorazgos". A lo que Villanueva y Torres le recordaron "que las ovejas eran del Papa, y que todos los Prelados eran sus súbditos". Con esta respuesta, le faltó tiempo a Siliceo para traer a colación el ardiente caso de la Reforma en Alemania y el comportamiento del papa con los prelados alemanes: "en Alemanía, decía Siliceo, habían los Germanos escrito al Papa centum gravamina, y que lo remediase y si no que le quitarian la obediencia, y que en España había estos y otros mayores gravámenes» ${ }^{21}$.

Ante semejantes juicios comprendemos el porqué ni notarios y eclesiásticos se atreviesen a presentarle las franquicias de sus enemigos. Con todo, el doce de diciembre se determinó que su defensor sería Francisco Martínez, notario apostólico; aunque se negó, en un principio, aludiendo miedo, poco después dijo estar dispuesto si le acompañaba "la parte».

\footnotetext{
Ibidem, pág. 191. de 1551

Ibidem, pág. 193. De estos percances escribieron a Roma los dias 15 y 20 de noviembre
} 
"Convinieron, pues, con el padre Villanueva que él entraría al Arzobispo y le leería la notificación". No hicieron efecto alguno estas diligencias, antes bien se acrecentó su acrimonía y odio, cargando de nuevo contra el Colegio de Alcalá. La polémica continuó muchos meses más. Villanueva, harto de todo, se fue un día derecho al palacio, y no tuvo ningún reparo en decirle a Silíceo que no le asistía ningún derecho a estorbarles ni mucho menos a ponerles impedimentos, tanto que "si no les daba libre licencia para hacer sus ministerios que él se la tomaría" 22.

Como en toda tormenta hay momentos de calma, en ésta también los hubo y un día parece que se encontraron ambos extremeños en son de paz, tratando de aliviar su cuitas, aunque, eso sí, poniendo en claro lo que les separaba.

La amistosa discusión que el "cleriguillo", apodo entre cariñoso y sardónico con el que Siliceo llamaba a su paisano Villanueva, se centró en tres puntos: el problema de la jurisdicción de los sacerdotes de la nueva orden; el excesivo número de jesuitas, unos quinientos eran los que en su opinión y en la de sus colaboradores habia en Toledo, y la exclusividad en usar el nombre de Jesús como distintivo de su orden, dejando el del Diablo al resto de los cristianos y órdenes religiosas.

A todas ellas contestó Villanueva con lucidez y verdad. El problema de la jurisdicción no significaba que los jesuitas fuesen como el toro de San Marcos, que pacía donde queria; los nuevos clérigos habian nacido, replicó como mejor pudo Villanueva, con la aprobación de la Santa Sede para ser y estar exentos de los obispos, acudiendo cuándo, dónde y durante el tiempo que ellos dispusiesen a cejercitar sus ministerios de predicar y confesar, que para servir y ayudar a los Prelados viene esta Compañía y Religión de nuevo". El segundo problema, el que en Toledo había quinientos jesuitas, fue rebatido en un santiamén; Silíceo vivía sumido en un grave error y confundia a los devotos de los jesuitas con los jesuitas; en Toledo no solamente no había jesuitas casados, sino que no había ninguno; el único y ocasionalmente era Villanueva. "Pues como me han dicho que hay más de quinientos y que de ellos son muchos casados". Respondió Villanueva, "ninguno puede ser casado, porque o son sacerdotes o se crían para ello; sacando los hermanos que se reciben para el servicio de los oficios a los cuales llamamos Coadjutores". Más llamativas eran las objeciones sobre el nombre; denominarse Compañía de Jesús no significaba que a las demás órdenes religiosas no les asistiese la

Ibidem, pág. 198 
gracia del nombre de Jesús, de la misma manera que llamarse otras de la Merced o de la Trinidad no significaba que en las restantes reinase la miseria o el espiritu del maligno.

No acaba aquí la historia, y lo que a continuación relataremos, creo, no como pretende Castro, que responde un poco al talante osado y atrevido de Villanueva y de sus primeros compañeros. Ante los más exquisitos refinamientos y galanuras del arzobispo y su servidumbre, respondió Villanueva con tal gracia y libertad que bien merece la pena que el lector conozca el colofón de la audiencia que vengo presentando.

"Habiendo acabado con el quisose ir porque era tarde, y dijole el Arzobispo, donde os vais Villanueva?, porque ya le habia reconocido por medio de sus padres que eran unos labradores de Extramadura, respondióle que tenia necesidad y iba a buscar de comer. Dijole el Arzobispo, quedaos a comer acá, aceptolo de buena gana y como se sentaran en la mesa, vido en su asiento un pequeño pan y dijo en voz alta a los que servian que le trajesen pan, y esto lo repitió no sé que veces con empacho de algunos caballeros que alli comian que condenaban su rusticidad. Trajeronle otros tres o cuatro panes y liegolos junto a sí. Trajeronle después una perdiz y con la hambre que tenia entregóse en ella y nunca la quiso dejar teniendo delante algunos otros platos que se habian servido; más detenianse comida la carne en roer sus huesecillos, quebrantándolos y dándoles una vuelta y otra, como si muriera de hambre y no tuviera otra cosa que comer. Todos los circunstantes estaban grandemente maravillados y aun corridos de ver cuan metido andaba Villanueva en sus huesos, y mirándosele el Arzobispo, le dijo, porqué no coméis de estotro Villanueva?, respondióle: Señor porque esto me sabe bien y estotro no sé como me sabrá; esto dicho, se riyó un poco el Arzobispo con los demás, y dijóle: comed, comed, Villanueva a vuestro placer de lo que os da más gusto» 23 .

No es de extrañar que ante este insigne y vociferante cardenal, Villanueva soliese "hablarle de dedo" ${ }^{24}$.

Finalmente, gracias a la intervención de personas autorizadas, el rey, el nuncio Poggio y otras personalidades, se revocaron los edictos, «mandando que dejasen a las personas de ella (Compañia) predicar, y confesar y celebrar y que todos los tratasen bien y con caridad", aunque el "Rector y Colegio de Alcalá y Religiosos de la dicha Compañía se sometiesen a su jurisdicción como lo estaban los monasterios de las órdenes mendicantes de su diócesis". Medida que en gran parte quedó sin valor, por cuanto el otro negociador, el padre Tablares, manifestó, por su parte,

Ibidem, págs. 201-202.

Ibidem, pág. 574. 
que los de la Compañía «en ninguna manera usarian de aquella provision, mas que predicarían, confesarían y administrarían los sacramentos, no teniendo respeto a las Letras del Arzobispo, sino a los privilegios que de la Sede Apostólica tenían con cuya autoridad harían el oficio que solían en los prójimos" 25 .

\section{Entusiasta, radical e ingenuo en el seguimiento del Señor}

Si hay algo en la historia de los primeros jesuitas y en la de los adalides de todas las órdenes religiosas es entusiasmo, radicalidad e ingenuidad en el seguimiento e imitación del Señor. Villanueva siguió al Señor en grado superlativo.

Su manera de vivir, en este punto se debe de hablar en plural, viajar, andar, comer ${ }^{26}$, vestir ${ }^{27}$, dormir y descansar fueron de auténticos pobres. Se cuenta de ellos que pasaban grande necesidad y pobreza; en los primeros tiempos de Alcalá, "aunque no faltaba a Villanueva la corta porción de Colegial, todo lo demás lo había de buscar de limosna y era de manera que con no tener que comprar algún libro viejo para el estudio, tomaba prestado el de otros compañeros, y trasladaba poco a poco las lecciones que en la semana siguiente se habian de leer" ${ }^{28}$. Vivian tan pobremente que "por falta de camas dormían de dos en dos y los manteos doblados servian de mantas y sobre ropas en el invierno"; para calentarse y cocinar - no debe olvidarse que uno de los problemas más graves de los pobres de todos los tiempos siempre ha sido la calefacción ${ }^{29}$ - se servian de "los miraveles que en el verano se hacian muy grandes los guardaban secos para leña en las quietes de noche de invierno"; comían de esta guisa: "al sentarse a comer poníase una escudilla para toda la mesa y cada uno iba echando en ella una tajada de lo que le daban y de esta manera se hacía una buena porción y acabada la comida la hechaba (sic) el refitolero en un pucherillo

\footnotetext{
25. Ibidem, pág. 220.

26. Gracias a la generosidad de doña Leonor de Mascareñas, nunca les faltó el pan ni la carne necesarios; la carne "como media asadura" semanal, la traian del rastro; "contentándose con yerbas cocidas a las noches".

${ }_{27}$ Villanueva vivió y vistió pobremente, "no mudando el hábito que traia, que era su manteo y sotana bien cortos y pobres".

28 lbidem, págs. $44-45$

29 Un estudio bien documentado sobre el abastacimiento de leñas para Madrid y de los problemas de la época Bravo Lozano, J., Montes para Madrid. El abastacimiento de carbón vegetal a la Villa y Corte entre los siglos xvil y xvil. Madrid. Caja Madrid, Colección Marqués de Pontejos, 1993, 322 págs.
} 
con su caldo y un panecillo y uno de casa se lo llevava (sic)» a una mujer pobre en que tiempos pasados "fue como madre para Ignacio, Mencia de Venavente ${ }^{30}$. Particularmente, Villanueva vivía lo más pobremente que podía. Castro afirma que amaba la pobreza como madre y la buscaba como los del mundo buscan las riquezas; vestía pobremente; comía "lo peor deseando tomar su comida en la cocina de lo que a los otros sobraba". Se sentía afrentado cuando le regalaban algo, sobre todo comida y siempre que peregrinaba su comida "era pan y un poco de queso» ${ }^{31}$.

Su extrema pobreza no les impedía ser agradecidos con los que les ayudaban. Desde el principio sintieron especial afecto por un anciano sacerdote, llamado Olmos, "que los confesaba y comulgaba" y como cayese «enfermo le traxó (Villanueva) a casa y le hizo curar con mucho amor, como si fuera un padre de la Compañía, todo el tiempo que duró la enfermedad y finalmente muriendo en casa le hizo enterrar con la solemnidad correspondiente exercitando su caridad en aquel de quien lo había recibido espiritualmente " ${ }^{32}$. Pero no sólo atendía a sacerdotes y personas de relieve, lo pobres eran su gran preocupación; los recibía a todos para hacer los "exercicios, dándoles si eran pobres la comida y cama sin interés alguno como a los de casa"; comportamiento en el que no estaban de acuerdo muchos de sus súbditos, más preocupados por su propia hacienda que por la del Señor, y que con cierta malicia le avisaban: "muchos se vendrán a exercicios por gozar del valato y comer y tener posada ser más de valde (sic)", "a lo qual respondia ojala viniesen mas que a todos los estudiantes pobres yo les admitiré y cuando no halla (sic) otra cama y comida quedalle yo les daré la mía a trueque de que ellos hagan los exercicios y se aprovechen y pluguiera a Dios que yo tuviese renta que a pobres y a ricos yo les diera la comida de valde (sic) mas placera a Dios que andando los tiempos tenga el colegio renta para ello" ${ }^{33}$.

Su generosidad se acrecentaba en las enfermedades de sus estudiantes. Una vez cayó enfermo uno, recetándole el doctor Mena medicina de

lbidem, págs. 598-599.

Ibidem. pág. 594. Merece la pena releer las páginas 595-597 en las que se nos cuenta la forma y el estilo, amén del espiritu, con los que vivía su confianza en Dios en medio de las escaseces, pobrezas materiales y proyectos de grandes empresas. Todo se le iba en confiar en Dios. trabajar de su parte cuanto podía, no hacer ascos a la albañilería ni al polvo ni, mucho menos, reprimir las hambres de sus jóvenes con advertencias de moderación en la comida. Las situaciones de escasez las resolvía diciendo y creyendo. "Comed hermanos y veved (sic) lo que hubisedes menester y servir al Señor que la bolsa de Dios es grande y no hos (sic) ha de faltar ". pág. 597 Ibidem, pág. 599.

lbidem, págs. 597-598. En estas páginas se dan noticias del pago de los ejercicios en Alcalá. 
valor. Mena, que conocía las entretelas de la casa, "dixo al Padre Villanueva: mire Padre que receto a peso de plata; a lo que Villanueva respondió, recete usted lo que mandare que para eso los cálices empeñare» ${ }^{34}$. Con los enfermos se saltaba los mandatos de Ignacio de Loyola, "se iba a la cocina y les quisaba lo que habian de comer» ${ }^{35}$.

La primera vivienda que tuvieron, gratis, y por la que pasaron cuantos ingresaron en la Compañia, se inauguró a finales del invierno de 1546; se trataba «de un patio, que era tal, que se le dieron de balde, solo porque le limpiase y aderezase". "Era este patio Ilamado por ignominia de Mataperros, o de los aguadores, el postrero de tres que hay detrás del Colegio de la Trinidad, y más apegado al muro de la Villa, el cual estaba tan sucio y tan lleno de tierras y basuras, y los aposentos pocos de él que había, tan deshechos y desbaratados que en él no habitaban otros que estudiantes pordioseros, y aguadores" ${ }^{36}$. Los oficios que en casas como éstas son muchos y variados se repartían entre todos; Villanueva, a pesar de sus muchas ocupaciones y ministerios, disfrutaba con los más exigentes y sacrificados: comprar y aderezar la comida ${ }^{37}$.

Esta vida, carente del alimento y del descanso necesarios, sobrecargada y llena de sobresaltos, fatigaba a los estudiantes y como pobres que eran, caían con frecuencia enfermos; el verano de 1547, agotados por el duro curso y por la falta de alimentación, no les quedó más remedio que emplearse en la limpieza y aderezamiento del patio y casa ${ }^{38}$; el trabajo debió de ser tan recio y los calores tan extremos que todos, excepto Villanueva que estaba fuera de Alcalá dando ejercicios, cayeron enfermos; al verano siguiente recayeron ${ }^{39} \mathrm{y}$ así sucesivamente hasta que advertidos por sus doctores amigos y con el miedo en el cuerpo de perder a los jóvenes, se trasladaron a un patio distinto y más "a propósito fuera de la puerta de Santiago, en unas casas de Atanasio de Salcedo, librero" ${ }^{40}$.

El concepto que Villanueva tenía de sí mismo era más bien pobre, y desde luego radicalmente distinto al que otros sentían por él. En 1548 le confesaba en carta a Ignacio de Loyola su falta de virtud, prudencia y letras. Loyola hizo caso omiso, enviándole, a cambio, meses más adelante,

Ibidem, pág. 599.

Ibidem, pág. 560, rep.

Ibidem, pág. 53

Ibidem, pág. 54

"Ellos esporteaban la mucha tierra que el patio habia y aliñaban los aposentos, y sacaron una puerta a la calle". Ibidem, pág. 55 .

39 Ibidem, pág. 66.

40. Ibidem, pág. 68 
el 25 de enero de 1549, "una patente de como su Santidad le acepta como Coadjutor", ordenado; es decir Ignacio de Loyola le mandaba se ordenase sacerdote. Villanueva se resistió con éxito hasta que el provincial Araoz hizo cumplir la voluntad de Loyola.

Mandado llamar a Valladolid, fue ordenado sacerdote el 15 de mayo de 1549, jueves de la Ascensión, por «el obispo de Tripol el obispo de Fuensalida de la Orden del Cistel (sic)" ${ }^{41}$. Ordenado, "pareciéndole que no sólo no hallaba en sí partes para el nuevo oficio .... se determinó de nunca decir Misa en la cual determinación pasó dos años hasta que forzado con obediencia rigurosa al fin la dijo".

Villanueva, que como muchos de sus contempóraneos, se sentía indigno, se había contentado con comulgar con encendida y ejemplar devoción cada ocho dias, prefiriendo estas devociones a la celebración de la misa. Loyola, que pensaba lo contrario, le ordenó "rigurosamente» celebrase su primera misa, concertándola para el domingo de Pascua del Espiritu Santo. Llegado el domingo de Pentecostés, aunque sólo fuera por no hacer un feo a los convidados y a los que habian aparejado la casa, no le quedó más remedio que obedecer. Nunca en su vida Villanueva celebró misa como la de aquel día.

\footnotetext{
"Teniamos una Iglesia tan pobre y pequeña que no cabian en ella una docena de personas y por esta causa se aderezó el patio lo mejor que se pudo con las colgaduras que proveyó don Jerónimo Viveros. Abad que fue poco después de Berlanga,... y con el cielo o toldo que para sombra del patio el año antes había hecho Don Juan de Borja... el altar se puso a la mano derecha del patio en aquella pared que está hacia la escalera principal. Llegado pues el día señalado llenóse el patio de la gente más principal de Alcalá, hombres y mujeres, y comenzó su misa aunque rezada, apadrinándole Don Luis de Viveros... y como la decía con cierto tono que toda la vida guardó suavisimo y devotísimo y con tanta consideración del oficio tan alto que hacia, fue tanto lo que se estremeció que a toda la gente hacia derramar copiosas lágrimas. Pero esto fue en mucho más aumento cuando diciendo el Credo, llegó a aquellas palabras venerables y llenas de todo consuelo: Et homo factus est; porque aqui ni el misacantano podia pasar adelante, sino que hubo de hacer una pausa notable, por el sentimiento y lágrimas que Dios le comunicaba, ni el auditorio pudo oir ni ver lo que pasaba por el nuevo sacerdote ni tener el mismo sentimiento. Predicó el Padre Fr. Muncio de la Orden de Predicadores... Habló en el sermón... del Misacantano según el amor y estima que de él tenía" ${ }^{42}$.
}

11 Ibridem, pág. 156

12. Ibidem. págs. 222-223 


\section{Fervoroso y consolado en su oración}

En este capítulo conviene ser lo más cautos posible. Resulta muy fácil mitificar los primeros tiempos e imaginarse cosas que no fueron. La historia, como veremos, desmiente estas mitificaciones, mostrándonos la complejidad de su vida y el lugar e importancia de la oración. Villanueva en este particular fue un auténtico maestro; maestro de cómo cultivar una vida espiritual que sin estar todo el tiempo en oración expresa, le capacitaba, le incendiaba, dirá él mismo, para vivir del amor y de la presencia de Dios durante todo el día.

No debemos, pues, imaginarnos a los primeros jesuitas todo el día en oración. Más bien nos deberiamos sorprender de su poca oración y de su falta de ritmo orante. El fervor, la comunicación explícita de Dios y de las cosas de Dios, sentimientos motivos al entusiasmo religioso y sobre todo a un crecimiento en fe, esperanza y caridad, les nacía no espontáneamente, o quizás sí, sino como respuesta agradecida a lo mucho que Dios hacía en ellos y por ellos. Después de la celebración de su primera misa el padre Villanueva "se sentía tan humillado de la merced tan soberana que Dios le habia hecho y tan agradecido a tan alto beneficio que muchos de aquellos días anduvo admirado de verse en tan alta dignidad de donde nacía que los pocos años que lo gozó no decía todos los días misa para más aparejarse y para decirla con más reverencia, sino algunas veces y éstas preveniéndolas, y leyendo antes la Misa un buen rato y muy despacio con atenta consideración de lo que había de hacer. Donde como una vez le preguntasen porqué no decía cada dia Misa, respondió que porque las ocupaciones temporales en que siempre andaba le traian distraido, y que cuando la había de decir quería decirla con mucha consideración... decíala de cuando en cuando apercibiéndose con mucho aparejo y leyendo primero la Misa que había de decir imitando a nuestro Padre Ignacio que así lo acostumbraba hacer, y decíala con tanta atención y reverencia, y juntamente con voz baja y sosegada que tenía con un tono suavísimo que parecía que la cantaba, con lo cual y porque de ordinario le daba Nuestro Señor lágrimas en la Misa, causaba en los que le oían mucha devoción. Con la misma suavidad y tono rezaba sus horas; y en lo que leía en el rezado de la Escritura le daba nuestro Señor sentimientos altísimos y para poderse acordar de lo que se le iba ofreciendo en el rezado, iba haciendo señales en el breviario y de aquí venía que cuando hablaba de Dios decía conceptos tan levantados no habiendo estudiado en estas letras nada; porque el autor de la Escritura se los comunicaba» ${ }^{43}$.

43 Ibidem, págs. 222-223 
Jesucristo era el centro de su vida. A los que quería bien les escribía, diciéndoles: "Jesucristo nunca se aparte de nuestra memoria porque en él siempre pensemos, ni de nuestro entendimieto porque a él siempre entendamos y conozcamos y muho menos de nuestra voluntad porque a el siempre amenos y su santa voluntad siempre hagamos. Amen" ${ }^{44}$. Su oración, en lo posible metódica, aunque no siempre lo conseguía, tenía como centro «la vida de Xto conforme los exercicios y no era nada devoto de otras contemplaciones singulares y éxtasis y arrebatamientos y solia decir que en esta vida no quería otras contemplaciones que la vida y muerte de nuestro salvador para solo imitalle" ${ }^{45}$. Su experiencia pastoral y espiritual le enseñó que "al alma se le ofrecian dos tiempos: un tiempo de necesidad" y otro de prosperidad. En el primero, que era el tiempo de los estudiantes y pecadores, tiempo en el que se sentían intensamente las muchas faltas y en el que se contaba con poco tiempo para "remediallas", era "menester acogernos a donde hallaremos el remedio más aparejado y meditar aquello en que hallaremos más devoción y aprovechar esto para la salud corporal'”, es decir era el momento adecuado para meditar y contemplar la pasión de Cristo, «porque no hace tanta fuerza el entendimiento alli donde es inclinado y fácilmente piensa lo que quiere y así no se dará la cabeza y el tiempo que había de gastar en aplicar el entendimiento a otra cosa lo gasta en remediar sus faltas y en venir en amor de Dios" ${ }^{46}$. El tiempo de prosperidad, cuando los estudios estuviesen concluidos y la vida y los negocios encarrilados, era el más indicado y conveniente para "sacar jugo para los próximos".

No sabemos el tiempo que dedicaba a la oración, pero sí que ésta era su primera obligación. El padre Castañeda, su compañero de cuarto, siempre se lo encontraba, cuando se levantaba, "hincado de rodillas y puestas las manos en oración"; de la oración, manantial de sus dones espirituales, era de donde sacaba argumentos para pláticas y ejemplos y luces para sus coloquios espirituales. No era nada extraño se emocionase cuando hablaba, "derramando lágrimas de devoción» ${ }^{47}$.

Esta forma de oración y lo que el Señor le daba a sentir no le libraba de broncas, riñas y peleas. Su temperamento ardiente, su resolución e intemperacia, le ganarian muchas personas para Cristo, pero también muchos mamporros para su rostro. En más de una ocasión le golpearon y él

Ibidem. pág. 582

Ibidem, págs. $589-590$

lbidem, págs. 573-574 rep.

Ibidem, pág. 589 
como fiel discípulo de Cristo se hincó en ambas de rodillas ${ }^{48}$, esperando recibir más; en otras, sin embargo, sobre todo cuando no le gustaba como trataban los oficiales y tenderos las cosas que con tanto esfuerzo habia adquirido, sacaba su genio y sin más las hacia ${ }^{49}$.

\section{Un hombre confiado en la victoria final a pesar de la desproporción entre los medios y los fines}

Llama poderosamente la atención que "un Hermano idiota y sin letras en una Universidad de tantas letras; un hombre desconocdo y destituido de todo genero de favor humano, entre gente de tanta autoridad y favorecida de los hombres" ${ }^{50}$, fuese capaz de transformar el ambiente de algunos colegios universitarios de una Universidad, la de Alcalá, no precisamente muy devota; no se entiende, tampoco, cómo un no sacerdote, un iletrado y un itinerante fuese capaz de llegar no sólo al corazón y sentimientos de sus interlocutores, sino también a la fuente a su inteligencia. Parece imposible que un hombre de formas bastante toscas -en esto se parecerá a otros hombres de su generación y a otros grandes apóstoles jesuitas como los padres Pascasio Broet y el gran Pedro Canisio- dos años después de establecerse en Alcalá contase con tantas amistades, entre las que habria que destacar un nutrido grupo de doctores, entre ellos Lartaun, más tarde obispo del Cuzco, Aguilera y Miranda, ambos vizcainos, Zavallos, el dominico Muncio. Resulta costoso ver en Villanueva el prototipo del apóstol moderno y sin embargo lo era. Era tal la confianza que tenía en sus fuerzas y en su experiencia que no temía hollar lugares para los que no estaba preparado y salir, como se verá en la siguiente anécdota, triunfante: "si me ponéis eso en términos que yo lo entendiera y habiéndolo declarado lo mejor que sabían les decía a eso no se ha de responder de esta y de esta manera y tocar su punto y la verdad tan bien

48 Por lo que significa relataremos uno de ellos. "Cuando estudiaba las fumulas en la universidad disputando con un estudiante y defendiendo con constancia su conclusión, envistióle (sic) al condiscipulo un espirito de ira con que alcanzando la mano le dio en su rostro una bofetada, y él luego inmeditamente se hinco de rodillas y le pidió perdón de la ocasión que para ello le habia dado". Ibidem, pág. 591.

as loidem, págs. 590-91. Se cuenta que cuando estuvo en Salamanca el año 1554 camino de Plasencia, acudió con el padre Portillo a la feria de San Miguel en el Teso, "y compró lienzo y lana en buena cantidad y echandolas ciertos hombres en sacas para llevarla a Plasencia viendo que no lo hacian a su contento se quitó su manteo y su sotana y comenzó a vistas de todos a llenar sus sacas hasta que las acabó con harta admiración y edificación del padre Portillo que se lo quiso estorvar (sic) y no pudo y de los que le veyan y de los de casa, que luego lo supieron"

50 lbidem, pág. 2. 
y acertadamente como si hubiera gastado su edad en leer aquellas dificultades.... no le faltaba más que los términos de las Escuelas» 51 .

\section{Un ser creativo e imaginativo}

Quizá ese liderazgo deba fundamentarse en su capacidad, más evangélica que socrática, para sacar provecho del material humano y de las inclinaciones y recursos, buenos y malos, de las personas con las que trataba. Villanueva, como todos los grandes de su época, destaca por su realismo. De un modo muy realista y práctico, sin más pretensiones que las de poner en contacto a los hombres con Dios, lograba de un modo intuitivo y espontáneo, que después cuidadaba y acrecentaba por medio de visitas y correspondencia, el cambio y la conversión de los hombres con los que trataba.

Paradigmática nos parece la historia de la conversión de una fraile lego, contumaz y bravucón, descuidado y perdulario, del monasterio de San Isidro, de la Segunda Regla de San Jerónimo de Tendilla, Villa del Marqués de Mondéjar, que por azares de la historia y por la apuesta comunitaria que sobre su persona hiciera otro fraile, paisano suyo, consistente en apostarse que si se conseguía la reforma de vida del lego por medio de los ejercicios espirituales toda la comunidad los practicaría.

El lego al que nos referimos era compañero de un padre de su comunidad, fray Pedro de Aragón, que de tapadillo había hecho los ejercicios con Villanueva en Alcalá. Vuelto a su casa, confesó la verdad, apostándose con sus hermanos que el más bárbaro y tremendo lego de su comunidad sería reducido y convertido por los ejercicios y por el padre Villanueva. Sus incrédulos compañeros le sonrieron con bastante sorna, como diciéndole que estaba loco. Su contestación siguió siendo idéntica: si el lego entraba en orden, la comunidad tenía que hacer los Ejercicios. Aceptada la propuesta pusieron camino de Alcalá al lego.

Su aspecto era "feroz, porque traía la barba grandísima, cual solían traer en aquellos tiempos los capitanes, y hombres valientes, pero muy más feroz en su condición porque no le pudiendo poner en orden sus frailes despues de muchos años que había estado en aquel convento, le habian querido algunas veces despedir de su Religión por incorregible. Mas por ser de gente principal en Aragón y por haber traído mucha hacienda a

s) Ibidem pág. 574 . 
la casa, y ser el por sí tan terrible no le osaban echar, pues como no hallasen medio para corregirle no hubo dificultad el Fray Pedro en persuadir a los demás que lo enviasen a Alcalá... si aquel fraile venía reformado todos irian hacer los ejercicios".

Los comienzos no pudieron ser peores. Al salir de su convento y cruzarse con los lugareños que le conocían y sabian mucho de su terquedad e intemperancia, le preguntaban con cierta guasa “donde iba, él respondia con risa y menosprecio; envíanme mis frailes a Alcalá a hacer no se qué diablos de hechizos". Su recibimiento no fue nada agradable ni aún para hombre con tan poca aparente sensibilidad; al no contar el colegio con portero fijo, se tocaba la campanilla y el primero que pasaba por el portalón o estaba cerca de la puerta corría los cerrojos. Sucedió que uno con "sayo pardo agironado a manera de los que traen los de Sayago y encima una sobreropa también de pardo y grosero, y lleno de cal y yeso, como hombre que andaba metido en obras de albañileria», le abrió. Cuál no sería su sorpresa cuando el lego le demandó por el padre Villanueva, y éste le respondió: "yo soy»; "como le oyó decir que yo soy, mirole el fraile después a cabeza y considerando su hábito y trage sin más hablar, vuelve la rienda (iba montado en mula grande) a la mula para irse, diciendo: no digo yo, mira a quién me envían".

Lo tardio de la tarde y la larga distancia de su convento, más alguna que otra porfía, retuvieron al lego, ocasión que aprovechó Villanueva al tiempo que le servía la mesa para hablarle "de Dios con tanto gusto del fraile, que dejando el comer se estaba espantándole oyendele". Testarudo como era, volviole a porfiar, amenazando con irse. Villanueva le ofreció techo y cama aquella noche y comenzó de nuevo a conversar de Dios y de sus cosas. "Al fin le vino a pedir le diese los ejercicios.... dióle los ejercicios teniéndole en sola la primera semana, veintiun dias, y quiso nuestro Señor tocar su corazón de manera que por todos aquellos días, dio a hacer extraordinaria abstinencia; y dar gemidos y sollozos, que toda la casa echaba de ver y hizo al fin una confesión general con tanto sentimiento y lágrimas que no lo podía encumbrir».

Unos cuantos meses después, a pesar de las prohibiciones de los superiores mayores, toda la comunidad de Tendilla habia hecho sus ejercicios.

Villanueva tenía especial gracia para la conversación, era ameno cuando lo tenía que ser y grave cuando lo exigian las circustancias. Se acomodaba a sus interlocutores, "levantando pláticas de la virtud de sus mesmos negocios". Escuchaba a los de dentro y a los de fuera y con todos procedía de manera semejante: «sacando de lo que le hablaban reglas 
de bien vivir que les daba", así como documentos religiosos ${ }^{52}$. A todos cuanto trataba "con sus pláticas pegaba fuego de amar la virtud" ${ }^{53}$. Para este menester usaba y espoleaba a los suyos a que leyesen con gran aparatosidad y solemnidad las cartas de sus compañeros, especialmente las cartas de las Indias de Javier; "las cuales tenían cuidado los de casa y en particular el Portero de dar a los estudiantes para que las leyesen juntándose de cuatro en cuatro y de seis en seis, leyendo uno con lo cual se movían muchos, y vez hubo que cuatro juntos pudieron ser recibidos en la Compañía, aunque fuese para ir a las Indías» 54.

\section{Un original y primitivo intérprete de la nueva espiritualidad de ignacio de Loyola}

Tan original y primitivo fue que sus interpretaciones, creo, le ocasionaron no pocos problemas. Su singularidad interpretativa le distanciará de los designados para estos cometidos, pero servirá para advertir que la regla, por muy universal que sea, nunca deberá ser interpretada universalmente.

Villanueva, imitando lo que habia vivido en Roma, ayudaba a sus escolares a consolarse y espolearse mutuamente; les "tenia señalados un rato de la quiete del mediodia del qual se sacaba mucha" edificación y consuelo ${ }^{55}$. Fue durante estos primeros años cuando Villanueva se mostró más maestro que nunca: les enseñaba, durante el rato que se juntaban las noches de invierno en la cocina, a sacar espíritu de todas las cosas que "había en la cocina y de otras muchas» ${ }^{56}$.

Su magisterio espiritual tuvo como norte la enseñanza y el ejercicio de "la abnegación y despego de las cosas y la voluntad indiferente para lo que los Superiores quisieren ordenar y Dios Nuestro Señor dispusiese ${ }^{57}$. Virtudes que exigian un raro equilibrio para que las reglas ${ }^{58}$ no fortalecie-

\footnotetext{
Ibidem. págs. 575. "A los caballeros y hombres de república les enseñaba como habian de gobernar cristianamente, a los labradores y gentes rústicas mostraba a vivir en virtud por semejanzas y razones tomadas de sus labranzas».

sit lidem, pág. 575.

s.s. Ibidem, pág. 321.

st Ibidem, pàg. 564 rep

st. Ibidem, pág. 564 rep

".) Ibidem, pág. 259

${ }_{s}$ Se seguian "ciertas reglas traidas de Portugal que estaban colgadas en una tabla del refectorio"; tenian seis horas de sueño... dos horas de oración... después de comer y cenar iban a dar gracias a la Iglesia y gastaban en esto un cuarto de hora cada vez. Ayunaban los viernes y sábados. Los exámenes de conciencia se hacian después de comer y cenar... Ibidem, págs. 319-320.
} 
sen las propias particularidades en detrimento de lo comunitario y corporativo. No era nada raro que, incluso a los ya formados, les mortificase, diciéndoles sus "faltas y decianselas dos o tres que el superior señalaba, oyendolas de rodillas...» ${ }^{59}$. Villanueva, en consecuencia, aprovechaba las sobremesas, momento en el que se encontraban todos juntos, para formarlos en la abnegación ${ }^{60}$, en la configuración de una nueva y difícil identidad y en la ayuda mutua; del nuevo religioso se decía «que el de la Compañía ha menester grande espíritu y grande calidad de mortificación y virtudes, porque si no tiene ésto faltándole el rigor exterior que otras religiones tienen con que se ayudan queda perdido"; se defendia que "debía un hombre mirar que hiciese todas las cosas por menudas que fuesen con gran pureza y perfección", se ponderaba, finalmente, "mucho y muchas veces lo mucho que Dios le daba en la Compañía por lo poco que había dejado en el mundo" 61 ; respecto a la ayuda mutua, dias antes de partir hacia Plasencia, "les juntó a todos y les trató del remedio de las faltas exortándolos (sic) a que se juntasen de dos en dos para que uno a otro le notase y advirtiese las faltas que hacia entre dia contra las reglas y otros descuydos se avisasen de ello con amor y caridad para enmendallos... A esta causa instituyó que cada uno tuviese a otro por superior para que le dixese sus faltas y le mortificase y fue costumbre que tuvo e introduxo N. Padre Ignacio en Roma" ${ }^{62}$. Todo esto, pienso tiene mucho que ver con lo que Villanueva sentía por la oración por el prójimo. A este respecto, pensaba Villanueva que el orante, en este caso el jesuita, no tiene que tener conciencia entre la oración por y para sí mismo y la oración por su prójimo, pues si «quando yo he conocido mis faltas y pido a Dios perdón de ellas pido juntamente para los próximos y presento juntamente mis necesidades y las de los próximos y para mas encenderme presentar si quisiese algunas particulares de mis próximos, ansi que vaya toda la oración con los proximos pues somos todos Hermanos y hijos de un Padre celestial y hemos de desear con igual deseo que se remedien las necesidades de nuestros próximos como las nuestras, de lo qual se sigue grande amor de los proximos y asi iremos adquiriendo el amor de Dios y del proximo de donde

59 Ibidem, págs. 319-320.

60 Ibidem, págs. 584-585. "Su ordinaria enseñanza era la abnegación de si mismo y despego de las cosas y ponerse indiferente a todo según la voluntad de Dios y de esto hablaba en pláticas espirituales y comunes".

61 Ibidem, págs. 366-367. Principios que tenia como particulares y propios el padre Juan Rodriguez, pero que creo entender eran extendibles y aplicables a otros muchos jesuitas y a la Compañía entera.

62 Ibidem, pág. 585 
pende nuestra salud" ${ }^{63}$. Por lo que nada debemos extrañarnos cuando afirme que el amor hacia los hermanos no basta con que sea interior, sino que "es menester también exteriormente mostrarle" ${ }^{64}$.

Entendia la abnegación, en la que trabajaba permanentemente, como el quebranto y rompimiento de sus voluntades. Una manera natural para ganar en abnegación era "hablar al superior de las cosas que uno lleva y tiene por dentro", y esto por dos razones: la primera, el no hablar es militar y andar en tentación; la segunda es no llegar a la indiferencia y no salir del egoísmo, de la soberbia y del engaño, amén de la verguenza que uno tiene en comunicar con quien más le conoce, y que para más señas está puesto en el lugar de Cristo como su vicario, "pues aunque sea malo comunica nuestro Señor su voluntad y lo que quiere que aquella persona haga y por otra persona, añade con cierta malicia o quizás experiencia, aunque sea buena no lo da todas las veces a sentir...» ${ }^{65}$; otra, aunque en mucho menor medida, era dar mortificaciones públicas como andar vestido como pobre ir en cuerpo con alguna sotana rayda a la doctrina traer agua de la fuente o de la plaza lo que se compraba y otras semejantes ${ }^{66}$; lo más conveniente y lo que más de acuerdo estaba con la nueva religión y con el ejercicio de la abnegación era seguir bastante de cerca a los estudiantes "tomando el pulso de cada uno y mirando en que oficios de humildad y abnegación seria bien exercitalle y en ellos les exercitaba así en casa como fuera de ella mirando solo el servicio de Dios y provecho de los sujetos y edificación de los próximos". Concedia a esto tanta importancia que "quando esto se ponia de por medio no perdonaba a qualquiera por más habilidad y letras que tuviese o por más caballero que fuese, o de otra condición antes a los tales procuraba más mortificar y ansí una vez les daba oficio de comprador, otras los enviaba al rastro y les hacia vender públicamente el menudo y traer a cuesta la carne y de la plaza la verdura y si algo faltaba en casa les hacía salir por las calles a pedir limosnas para comprallo" ${ }^{67}$.

Respecto a las penitencias corporales, su enseñanza era la moderación; creía era mejor cansarse con las cosas de la vida que azotarse desesperadamente. No le temblaba la mano con los que se pasaban en este capítulo, pues la regla era "sugetar al cuerpo y no matalle» 68 ; la reinci-

lbidem. págs. 576-577 rep.

Ibidem, pág. 579

lbidem, págs. 577-578 rep.

loidem. págs. 585-586 y 562-563 rep.

Ibidem, pág. 563 rep.

Ibidem. pág. 586 . 
dencia en este tema podia significar la expulsión del reincidente de la Compañía ${ }^{69}$.

Los temas a los que más atención prestaba eran los de la obediencia y seguimiento del Señor en medio del mundo y al más puro estilo de la itinerancia. "Porque el Instituto de la Compañia no es estarse un hombre recogido en su aposento sino de tal suerte entender en las ocupaciones y negocios de los próximos en que los pone la obediencia como si se estuviera dentro de ella siguiendo las pisadas de Cristo N. Sr. y de sus sagrados Apóstoles a quien en nuestro modo de vida tenemos por dechado y a quienes siguio N.P. Ignacio con todos los demás sus compañeros ${ }^{70}$.

No menos importante era la práctica del examen particular de conciencia; lo consideraba «el instrumento inmediato para alcanzar la pureza del corazón"; se iniciaba "escudriñando los rincones de vuestra alma" para luego ir "al amor de Dios y si Nuestro Señor no os diese no procuréis trabajar la cabeza por alcanzar más estaos en vuestra miseria y poneos delante de la presencia de Dios como un hombre desambrazado lleno de llagas de pecados y miserias y llamad a la puerta de su misericordia y si os diese limosna bien y si no paciencia y esperar con perseverancia y no os vayais luego que los pobres suelen esperar a la puerta hasta que les dan limosna" ${ }^{71}$; lo esencial del examen era "no curar de hacer mucha fuerza discurriendo en lo que he faltado sino mirar más en los apetitos y aficiones desordenadas y tener gran aborrecimiento de ellas proponiendo muy de veras la enmienda en adelante" ${ }^{72}$; su gran detractor era el demonio, pues conocedor de su importancia "pone tantos impedimentos para que no se haga o no se haga bien y asi veréis, añadia, que con tratar de ordinario los de la Compañía a exercicios de oración poquísimos hay que hagan este examen y muchos menos que lo hagan con provecho" ${ }^{73}$.

Quizás donde mejor se observa su magisterio espiritual y su capacidad interpretativa y asimilativa de la nueva espiritualidad de la Compañía de

69. En esto como en otras cosas Villanueva parece que no fue muy consecuente y que de no haber entrado en la Compañía hubiese sido un duro castigador de su cuerpo. Cuando estudiaba en Alcalá y le entraba gana antes de llegada la hora de comer, "se salía por la orilla del rio y solia coger algunas varas delgadas de sauce o mimbre y con ellas volvía a casa y se castigaba antes de comer en pena antes del apetito antes del tiempo de la comida». Ibidem, pág. 595.

(0) Ibidem. pág. 587. En otros pasajes de este libro se dice que se tomaba esto tan en serio que «andando siempre en su divina presencia que le causaba tanto dolor en la cabeza que le era a veces necesario echarse en ella jarros de agua fria"... pág. 589.

lbidem, págs. 569-570 rep.

Ibidem, pág. 580 rep.

Ibidem, pág. 588. 
Jesús es en las respuestas que le pedian sus estudiantes. El que luego sería gran predicador, el padre Juan Manuel, le preguntó una vez, ¿qué tengo que hacer cuando "estoy todo el día metido en mis estudios y cuando voy a la oración hallome seco y vieneme a la memoria lo que estudio"? ${ }^{74}$. "Los estudios los tenéis que tener como oración... de manera que el fin y el blanco de los estudios ha de ser agradar a Dios y cumplir su santa voluntad en el superior que os manda estudiar de tal manera"; "porque andando el tiempo el superior puede mandar ir a la cocina, ser acemilero o lo que se le ocurra. Entonces si se estudiaba por amor propio costará mucho esfuerzo hacer otra que no sea lo que quiere el propio amor»; el ideal es hacer lo que el superior mandase "y de esta manera todas las cosas cada una de ellas os será como oración y os dará Dios Ntro Señor grandes sentimientos y consolaciones y si uno por sólo el amor divino se diese a las letras vendría a sacar por ventura más fruto de leer en un Terencio que otro de leer en un libro de muy devoto". Lo determinante en ésta y en otras acciones era poner en primer lugar a Dios y esperar que estas acciones, hechas por amor a Dios, por muy seculares y mecánicas que parezcan, se conviertan en alimento del espíritu y de la voluntad.

No era esto lo que los estudiantes hacian y pensaban. Por ello Villanueva continuaba con sus apostillas, preguntándoles: “¿sabéis que es lo que solemos hacer?. Entramos al estudio con Dios y salimos con nosotros", sin percibir, una vez metidos en el estudio con el afán y concentración necesarios, la propia voluntad y los "apetitos naturales de saber y estudiar», y lo que es peor sin advertir que con el paso del tiempo, "os apegáis tanto a ellos que después si os sacasen de ellos para algún oficio humilde sentiriades bien la enfermedad oculta y se descubriria la celada de la propia voluntad y os hallariades inquieto y desasogado"; para salir seguro vencedor en negocio tan cotidiano como vulgar en la vida del estudiante, advierte Villanueva: «mirad si después de haber estudiado quedáis quieto, sosegado y devoto y sin remordimiento que si ansi quedáis señal es que lo haciades por amor de Dios, pues se quieta la conciencia que es señal que está el alma en su propio lugar y centro natural»; lo contrario, cuando "el anima va contra su naturaleza y con la violencia que lleva se causa inquietud y se sospecha de la obra pasada", "señal es que no ha ido por puro amor de Dios, más por propia inclinación y apetito", no estando indiferente y guardando todo para sí y nada para Dios. "Así que entendemos de aquí que la causa de que el estudio se siga inquietud y impedimento para la oracion, es porque apegamos demasiado nuestra vo-

Ibidem. pág. 566 rep. 
luntad a él, la qual Hermano, si despegáis y os ponéis indiferentes teneis el remedio, que pedis en vuestra pregunta" ${ }^{75}$.

Pero como hemos dicho anteriormente, Villanueva aprovechaba preguntas generales para examinar y responder por su medio cuestiones colaterales. Para Villanueva en todo se tenía que procurar «la confusión y la anichilación propia mirando de nuestras imperfecciones, y este es el camino real por donde N. P. Ignacio quiere que caminen todos los que en la Compañía de Jesús están, y en esta necesidad presente cierto tenéis harta materia de confusión que para los estudios estáis tan dispuestos y estudiais con tanto conato y voluntad". Si llega uno a la oración torpe y como imbécil, lo que esa persona, a no ser que se encuentre muy agotada o enferma, está transparentando de su vida interior, de su pura intencionalidad, es su alejamiento "del verdadero aprovechamiento" y de la "perfección». Y no contento con esta conclusión, pedía a sus estudiantes que estas aptitudes las hiciesen extensivas a otros negocios de su incumbencia, que «si bien mirais como os hallais en los otros exercicios hallaréis la misma falta en todos y así se os ofrecerá harta materia de confusión". En consecuencia, convenía entrar con humildad en todas las actividades, pues entonces "no hay duda sino que Nuestro Señor os hinchará de sus dones". Lo decisivo de esta nueva vida y del nuevo tipo de religioso era ganar y crecer siempre en amor de Dios. Toda actividad debería concluir con actos de "amor de Dios", para así estar continuamente inflamados y "con vivos y ardientes deseos descubrirle y padecer por él y quedaros con esos deseos". $Y$ para conseguir esto, además de la diligencia necesaria, recomendaba mucha paciencia y humildad: "asi vos Hermano habéis de esperar con humildad y no esperar y pensar que a fuerza de brazos habeis de alcanzar lo que queréis porque esto es sovervia (sic) y no alcanzareis nada y mas que os echareis a perder y enfermareis la cabeza de tal manera que no sereis en toda vuestra vida mas para horar (sic) y os quedareis inutil y sin provecho". Cosa bastante difícil de conseguir, sabida la natural intemperancia de los jóvenes, por lo que mejor era "no hacer fuerza para sacar sentimiento sino estaos como dixe en vuestra propia miseria y no penséis entrar a la casa de Dios por fuerza de cabezonadas sino rogando con humildad... si le pedis alguna cosa y no os la concede creed que lo hace por vuesto provecho porque sabe bien que en aquel tiempo y en aquella disposición no conviene aquello..." ${ }^{76}$. Si a base de paciencia, ensayo y esperanza en la acción del Espíritu se conseguía hacer

Ibidem, págs. 566-569 rep.

lbidem, pág. 573 rep. 
del estudio oración, del trabajo oración, de la vida oración, se lograría, por una parte, una unidad de vida y se acabaria formando parte, por otra, de una manera natural y no forzada, de la nómina de los nuevos apostoles.

A la pregunta: "si será bueno para venir al remedio el recogimiento y del hablar hacerme por algunos días extraño a los hermanos y apartarme de las conversaciones y no hablar para venir a no hablar superfluo" ${ }^{77}$, que nos advierte de lo poco asimilada que estaba la nueva espiritualidad y de los peligros espirituales que se cernían sobre este grupo humano en el futuro, respondia: «me parece que no es bueno eso sino que habléis y converseis con los hermanos el tiempo que los otros y que os acostumbreis a hacer todo a todos"; miren "al espiritu de la Compañia que no quiere que esteis siempre encerrados en una cámara", sino "que llevéis el recogimiento que tiniades en vuestra cámara y cobreis habito de estar en conversación y deste cobrareis gran quietud porque si solo en vuestra cámara estais acostumbrado a estar advertido y recogido quando sea necesario salir a tratar y conversar con los próximos estareis inquietos y desasogados, mas si procurais hallar a Dios en todas partes os aprovecharais... pues si los de la Compañia son llamados para tratar con los próximos es menester que se hagan a las armas... Dios quiere que entre el gozo contento y alegria que ay (sic) en la Compañia hallemos y el se nos da". Y terminaba con estas palabras: "creed hermanos que en nuestra conversación en Dios ay grande provecho para el cuerpo y para el alma acrecientase la caridad y unión entre los Hermanos, huyen las tentaciones y las tristezas y cobrase libertad de espiritu, más si os apartais y haceis extraño vereis que de adios hacen y que sobrecejas y asperezas con todos que despegamiento con los hermanos y juicios y otros mil inconvenientes y enfermedades de cuerpo, asi que esto quiero yo de todos los hermanos que se habituasen a hablar a Dios en todas partes" ${ }^{78}$.

VIII. Todo ello tamizado por su singular carácter y fuerte personalidad, temperamento que no claudicó ni ante hombres tan de carácter y reciedumbre como Ignacio de Loyola, Miguel de Torres, el Cardenal Siliceo y Jerónimo Nadal, obispos, abades, priores y altos profesores de Universidad por decir algunos de sus interlocutores y "contrincantes".

Su temperamento, pienso, queda claramente reflejado en las duras palabras que tuvo con el obispo de Plasencia, Gutierre de Carvajal, aficio- 
nado a los jesuitas, pero un tanto timorato a la hora de acometer la reforma de su diócesis. Villanueva, que prefería la reforma de la diócesis y no la apertura de un nuevo colegio, fue directamente al obispo y "con la santa libertad que tenía, lo primero con que le entró fue decirle aquí nos trae V. I. para hacer fruto en sus ovejas, pero es necesario comenzar por su $V$. I., la cual palabra le causó no poca novedad, porque nunca hombre se le había atrevido a decir cosa semejante, más fuele el Padre Villanueva con su trato y conversación cautivando de manera que el que antes había sido más príncipe y Señor de Corte que Prelado Eclesiástico de tantos brios, pundonor y respeto que a ninguno reconocía por ser hombre muy soldado en sus obras y tratos. Vino poco a poco a ablandarse, humillándose y rindiéndose " ${ }^{79}$. Pero don Gutierre, que actuaba un tanto cicateramente, no estaba dispuesto a ceder parte de su huerta para levantar el colegio que tanto decía querer. Esto provocó que Villanueva se arrancase con una de las suyas: "empezó delante de él a medir un pié tras otro hasta siete en largo, y preguntándole el Obispo qué hacía respondió: para mi Señor llustrísimo bastanme estos siete pies de tierra que mañana me moriré, pero no lo que está señalado por $V$. Señoría para un tan principal Colegio como V. S. ha comenzado, y a mí poco me cuesta volverme a mi Colegio de Alcalá con mi manteo al hombro y mi breviario como vine".

Esta desbordante libertad interior estaba acompañada de cierta indisciplina en materias litúrgicas, que por entonces en toda la Iglesia comenzaba a uniformarse. Su amigo y compañero, el disciplinado padre Miguel de Torres, aprovechó la cuaresma de 1557, camino de Roma para asistir a la primera congregación general, para examinar de cerca la vida y la marcha del colegio de Alcalá. Torres no estaba de acuerdo con el modo cómo se celebraban las misas ordinarias ${ }^{80}$ : "cada uno dice la misa a su modo, conforme a su gusto, teniendo regla en contrario, es a saber, que todos tengan un modo en palabras y ceremonias '; si mala era esta falta, más graves eran sus consecuencias, pues "lo que más se ha de sentir y llorar es que de estas libertades bienen (sic) los súbditos a hacerse propietarios en sus juicios, dando orden de vivir cada uno según su cabeza, y sentido, desuniéndose más y harto más de lo que conviene de la cabeza y de los

\footnotetext{
79 lbidem, págs. 344-45.

80 No conozco el ceremonial que se seguia en la celebración de la eucaristia. Me hace sospechar un texto de la página 562 que cada uno la decia según le inspiraba su devoción y que desde luego San Ignacio tenia el suyo propio. Pues en conversaciones mantenidas entre Nadal y Torres eran conscientes del particular modo que tenia de celebrar la misa Ignacio, "que hacia un memorial que se habia de tener y que hasta entonces no importaba que siguiese cada uno su devoción"s.
} 
otros miembros que procuran unirse con ella". Tan grave le parecia el asunto, que después de una serie de fuertes consideraciones espirituales, le instaba "se acuerde de estas cosas y de su remedio porque es mayor la necesidad de lo que parece", pues "el no hacer caso de estas cosas que tienen parecer de pequeñas es una máscara o por mejor decir una lima sorda que abre y descerraja sin que se sienta muchos candados y cerraduras porque de aquí viene el no haber aun bien ha ganado uno salir del encerramiento de la primera probación y exercicios cuando le ponen a confesar y decir misa públicamente como ya admitido e incorporado en la Compañía y viene a decir misa públicamente en la Iglesia» ${ }^{81}$.

Pero en lo que no cedió, manifestando su carácter y genio, fue en que ciertas personas, bajo capa de bien y con muestras de gran educación e interés, especialmente personas laicas y autoridades universitarias, le gobernasen su colegio y le seleccionasen las vocaciones. Se corrió el año 1552 que los mejores alumnos de la universidad se hacian jesuitas, cosa harto difícil, pero que indudablemente incomodaba bastante a rectores y profesores. Con la arrogancia que caracteriza a este estamento comenzaron a frecuentar el colegio de Villanueva; salían asustados y no se explicaban qué podian darles a jóvenes de tantas y excelentes prendas, con un futuro más que asegurado, para que viviesen en medio de la más extrema pobreza y estrechez, hasta no poder pagar unos reducidos censos. Se ofrecieron a remediar tal indigencia, si se les concedia ser examinadores de los candidatos. Villanueva no se dejó vencer por tales promesas, respondiéndole "que él procuraría pagar su censo, que a Religión no se había de recibir a nadie por aquellos medios ni jamás se vio que a seglares se tomase parecer en tales casos" ${ }^{82}$.

Villanueva, con todos su pros y contras, representa, pienso, al nuevo apóstol de la España moderna. Su manera de proceder, pero sobre todo su forma de entender y vivir la espiritualidad sacerdotal, en un mundo dominado totalmente por una religión, excesivamente vinculada a estereotipos y en nada alejada de supersticiones y exageraciones, le constituirán en sus sucesores en un apóstol, hábil y capacitado, entrenado, en suma, para rastrear la presencia amorosa de Dios en la tierra y en el corazón de los hombres.

4: Ibidem, págs. 557-560

$8^{2} \quad$ Ibidem. pág. 234. Además debe contarse el caso del padre Castañeda y su enfrentamiento con la Marquesa de Mirabel, que fue duramente zaherida cuando hacía comentarios y precisiones de poco gusto sobre la Compañia. Ibidem, pág. 265 